\title{
PROPOSTA DE MELHORIAS NOS PROCESSOS OPERACIONAIS NA GESTÃO DE COMPRAS: ESTUDO DE CASO NA EMPRESA FÊNIX IMPORT - ASSISTÊNCIA TÉCNICA
}

\section{ARTIGO ORIGINAL}

BARBOSA, Mikaele Da Silva ${ }^{1}$, MANTILLA, Angélica Maria Buitrago Acosta ${ }^{2}$, MOTTA, Edwin Bastos Sodré da ${ }^{3}$, ROBERTO, José Carlos Alves ${ }^{4}$,

BARBOSA, Mikaele Da. Et al. Proposta de melhorias nos processos operacionais na gestão de compras: estudo de caso na empresa Fênix Import - Assistência Técnica. Revista Científica Multidisciplinar Núcleo do Conhecimento. Ano 06, Ed. 05, Vol. 05, pp. 05-27. Maio de 2021. ISSN: 2448-0959, Link de acesso: https://www.nucleodoconhecimento.com.br/administracao/processosoperacionais, DOI: 10.32749/nucleodoconhecimento.com.br/administracao/processos-operacionais

\section{RESUMO}

O presente artigo tem como objetivo geral melhorar os resultados operacionais através da otimização dos processos de gestão de compras. Com a finalidade de intervenção é apresentada neste trabalho a implementação de melhoraria os resultados operacionais através da otimização dos processos de gestão de compras. E os objetivos específicos delineados são: Identificar potenciais fornecedores no

${ }^{1}$ Graduando no Curso de Administração.

2 Graduando no Curso de Administração.

${ }^{3}$ Graduando em Administração.

${ }^{4}$ Orientador. Mestrado profissional em Engenharia de produção. Especialização em Gestão em Logística empresarial. Graduação em Administração com Ênfase em Marketing.

RC: 84723

Disponível em: https://www.nucleodoconhecimento.com.br/administracao/processosoperacionais 
cenário nacional e internacional, avaliar quais insumos possuem mais demanda dentro da empresa e propor uma ferramenta para melhorar a gestão de relacionamento da empresa. Usamos a metodologia $5 \mathrm{~W} 2 \mathrm{H}$, que é uma técnica importante que pode ser utilizada para determinar alguns pontos a serem implementados. E quanto aos meios: estudo de caso, com um levantamento bibliográfico e análise documental. Contudo, o objetivo do nosso trabalho foi alcançado com êxito através de análises das pesquisas realizadas, foi desenvolvido um projeto para melhorar os resultados operacionais através da otimização dos processos de gestão de compras.

Palavras-Chaves: Gestão de compras, Fornecedores, MRP, Estoque, Negociação.

\section{INTRODUÇÃO}

No decorrer dos tempos, a função de comprar se tornou imprescindível para a administração dos recursos de materiais de uma empresa. No século XXI é fundamental saber comprar de maneira que possa gerar benefícios para a organização, visto que é um fato determinante, não somente para questão da competitividade, como para a permanência da mesma no mercado.

Nesse contexto, gestão de compras é uma ação essencial no que se refere ao bom gerenciamento das organizações, na qual interfere diretamente em seus estoques e na sua relação com os clientes, estando também direcionada ao sucesso da organização e a competitividade. A aquisição de matérias-primas de uma empresa retrata um agente primordial na atividade da organização, pois conforme é realizada pode possibilitar uma redução nos custos e benefícios nos lucros.

Em outro aspecto, a gestão de compras proporciona que a organização aperfeiçoe seus procedimentos e disponibilize ofertas de alta qualidade. Ou seja, quando as empresas optam pelas melhores decisões de compra, isso acarreta em uma maior segurança referente a qualidade do produto disponibilizado para o consumidor. Nesse

RC: 84723

Disponível em: https://www.nucleodoconhecimento.com.br/administracao/processosoperacionais 
entendimento, o crescimento da qualidade em uma empresa, gera fatores benéficos nos processos, que podem ir da gestão da cadeia de abastecimento ao planejamento estratégico

Por meio do Diagnóstico Organizacional, na empresa Fênix Import - Assistência Técnica, verificou-se a existência de problemas a serem melhorados, tais como nos processos operacionais de gestão de compras. Assim, por meio das pesquisas, identificou-se a necessidade de apresentar uma proposta de otimização dos resultados operacionais através das melhorias dos processos de gestão de compras.

Para essa proposta de solução o objetivo geral foi definido como: melhorar os resultados operacionais através da otimização dos processos de gestão de compras. E os objetivos específicos delineados são: Identificar potenciais fornecedores no cenário nacional e internacional, avaliar quais insumos possuem mais demanda dentro da empresa e propor uma ferramenta para melhorar a gestão de relacionamento da empresa.

\section{FUNDAMENTAÇÃO TEÓRICA}

A revisão bibliográfica inclui a revisão de artigos, textos, proposição de ideias de outros autores, não apenas citando opiniões, mas também comentando, contatando e até mesmo criticando as opiniões uns dos outros, e usar isso como base para a interpretação dos dados (KOCHE, 2016, p. 101).

\subsection{GESTÃO DE COMPRAS}

O ponto que necessita de mais atenção dentro de uma empresa, com certeza é a gestão de compras. Pois a escolha adequada de fornecedores, além de uma boa negociação de preços são imprescindíveis para se destacar perante os concorrentes, gerando um valor no mercado. Se a gestão de compras for eficaz pode proporcionar mais agilidade nas operações realizadas pelas empresas e a qualidade gradual das

RC: 84723

Disponível em: https://www.nucleodoconhecimento.com.br/administracao/processosoperacionais 
compras, o que para a organização é uma característica diferenciadora, positiva e competitiva.

Segundo Monte (2015, p. 155) a gestão de compras é um seguimento da cadeia de suprimentos encarregado pela integração entre a empresa em análise e suas ligações a quantia na cadeia.

Para Sousa et al. (2016, p. 45) enfatiza que para um bom desempenho de uma empresa, é fundamental uma gestão correta no processo de compras, mas essa importância depende de vários fatores, como a natureza da empresa ou o grau de dependência de terceiros. Independentemente desses fatores, sua boa gestão e desempenho são fortemente apoiados por uma área de compras bem estruturada.

De maneira geral, a gestão de compras é uma ferramenta importante para as operações da empresa e precisa ser analisada, pesquisa e ajustada de acordo com as carências do mercado. Portanto, a fusão de empresas com interesses correspondentes pode promover os benefícios consideráveis da aquisição de materiais.

\subsection{COMPRAS E CADEIA DE SUPRIMENTO (SUPPLY CHAIN)}

Existem no âmbito acadêmico como no empresarial, várias concepções para o termo Gestão da Cadeia de Suprimentos ou Supply Chain Management (SCM). Entretanto, se compreende que a Cadeia de Suprimentos aglomerado de ações direcionadas à extração da matéria-prima, que vão desde os processos de criação do produto até a chegar ao consumidor final.

Para Gomes e Neto (2015) diz que que a cadeia de suprimentos é multifuncional, envolve diversas áreas tradicionais das organizações. A SCM pode ser considerada como uma área atual, tendo variadas origens. Ou seja, ela pode ser apontada com um ponto de concordância de outros setores tradicionais no ambiente empresarial.

$\mathrm{RC}: 84723$

Disponível em: https://www.nucleodoconhecimento.com.br/administracao/processosoperacionais 
Para Gomes e Ribeiro (2020, p. 65) é importante destacar que a cadeia de suprimentos envolve todos os estágios implicados direta ou indiretamente. Englobando fornecedores, fabricantes, como também depósitos, transportadores, varejistas e clientes. No ambiente interno das empresas, a SCM integra todas as atividades relacionadas ao pedido, como finanças, marketing, entre outros. A cadeia é vista como dinâmica, pois compreende um fluxo contínuo de produtos, informações e capital.

A SCM é considerada um processo estratégico, que trabalha com previsão de demanda, seleção de fornecedores, contratos, transações financeiras, fluxo de materiais etc., para criar novos locais de hospedagem, como armazéns, fábricas etc., interagir com os clientes, e interagir com sociedade e meio ambiente., existem problemas mais abrangentes em economia etc.

\subsection{MRP}

O MRP permite que as organizações calculem quando certos tipos de materiais críticos são críticos. Para fazer isso, ele usa os pedidos da carteira e as expectativas dos pedidos que a organização pensa que receberá. Desta forma, o MRP irá analisar todos os componentes e elementos básicos para complementar o pedido para garantir a garantia em tempo hábil.

Para além disto, Pereira et al. (2016, p. 13) fala que o sistema MRP autoriza o cancelamento de ordens, assim como, a alteração nas quantidades de encomendas, antecipação ou não das datas de entregas, fornecimento de informações que proporcionam a visualização do planeamento das encomendas de material anteriormente ao registro das ordens.

O sistema MRP foi concebido, segundo Medeiros e Pereira (2018, p. 21) que os produtos em estoque são compartilhados em dois grupos: produtos de demanda dependente e os produtos de demanda independente.

$\mathrm{RC}: 84723$

Disponível em: https://www.nucleodoconhecimento.com.br/administracao/processosoperacionais 
Um conceito amplamente utilizado no sistema MRP é o tempo de espera, que se refere ao tempo entre o momento em que os materiais são solicitados de um fornecedor de materiais e quando são inseridos no estoque. Em relação à produção, o lead time pode ser entendido como o tempo entre a ordem de produção autorizada e o momento em que o produto é disponibilizado pelo cliente.

\subsection{ESTOQUE}

Estoque são os materiais ou produtos que a empresa pode realmente usar para a empresa antes de entrar no processo de produção ou continuar a vender ao consumidor final. $\mathrm{O}$ estoque pode ser matéria-prima e outros insumos, produtos em processamento, produtos acabados disponíveis para venda e estoque de todos os outros materiais e insumos que a empresa usa e precisa armazenar em suas instalações.

Na opinião de Paoleschi (2018, p. 78), O conceito de estoque é: qualquer quantidade de bens tangíveis armazenados de forma não produtiva dentro de um determinado período de tempo; o estoque é composto de produtos acabados e matérias-primas aguardando para serem vendidos ou despachados.

No entendimento de Santos e Lubiana (2017, p. 99) o estoque se expressa de três formas: de acordo com o tipo de empresa em questão, o estoque tem diferentes significados, mas sempre traz o significado de algo que pode ser utilizado, seja venda (como produtos comerciais ou produtos industriais), seja usado Quer seja usado para processamento (como matérias-primas ou materiais em processamento) ou para consumo (o estoque de materiais consumíveis pode ocorrer em empresas comerciais, industriais e de serviços).

A razão pela qual o estoque é considerado um ativo tão importante é porque ele pode ser um item decisivo na estrutura de cálculo do balanço patrimonial. Se a gestão da

RC: 84723

Disponível em: https://www.nucleodoconhecimento.com.br/administracao/processosoperacionais 
empresa o aplicar corretamente, seu controle pode levar a bons resultados financeiros.

\subsubsection{ESTOQUE MÁXIMO}

Na perspectiva de Paoleschi (2018, p.101) o sistema de estoque máximo consiste na verificação do nível dos estoques em intervalos fixos (semanal, quinzenal ou mensal) e estimando a quantidade necessária para completar um nível de estoque máximo previamente calculado.

A expressão utilizada para o cálculo de estoque máximo é:

$E \max =D \times(L+I)+E s$

$\mathrm{D}=$ Demanda

$\mathrm{L}=\mathrm{Tempo}$

I = Intervalo de revisão

Es: Estoque de Segurança

\subsubsection{ESTOQUE MÍNIMO}

Segundo Paoleschi (2018, p. 101), o objetivo do estoque mínimo é manter um fluxo de consumo ininterrupto em caso de abastecimento e / ou consumo anormal. Vamos considerar exceções, especialmente atrasos no tempo de entrega do fornecedor e acelerar o consumo.

Fórmula simplificada do estoque mínimo:

$E$ min $=($ consumo $X$ atraso no prazo de entrega $)+($ prazo de entrega $X$ aumento do consumo) + (atraso na entrega $X$ aumento do consumo).

RC: 84723

Disponível em: https://www.nucleodoconhecimento.com.br/administracao/processosoperacionais 


\subsection{GESTÃO DE CADEIA DE SUPRIMENTOS}

A cadeia de suprimentos inclui todas as partes relacionadas ao cliente que fez o pedido, mesmo as partes indiretas. A cadeia de suprimentos consiste em fabricantes, fornecedores, depósitos, varejistas e clientes. Dentro de cada organização e fabricante, a cadeia de suprimentos inclui todas as funções envolvidas no recebimento e na satisfação dos requisitos do cliente.

Segundo Magalhães (2015, p. 134), afirma que é comum utilizar a expressão Rede de Suprimentos, ao invés de Cadeia de Suprimentos, salientando que a sistemática da cadeia de suprimentos submete-se a uma sequência linear de processos efetuados em uma ordem, onde a interação direta com o cliente final é feita praticamente e exclusivamente através pelo elo final da cadeia.

Para Coti-zelati e Moori (2014) afirma-se que, no século passado, a integração entre os diversos elos da cadeia de suprimentos era um conceito vago. Devido à falta de experiência no assunto, a integração da cadeia de suprimentos torna-se desvantajosa e, quando surgem alguns problemas, a empresa só consegue se concentrar em si mesma. O objetivo, não na própria cadeia. No entanto, em meados da última década do século 20 , os arranjos de canais de distribuição tradicionais começaram a considerar mais integração e colaboração.

A gestão da logística faz parte da gestão da cadeia de abastecimento. Planeja, implementa e controla processos eficazes e eficazes e inverte o fluxo e armazenamento de mercadorias, serviços e informações relacionadas entre o ponto de partida e o ponto de consumo para atender às necessidades dos clientes.

\subsubsection{TÉCNICAS DE NEGOCIAÇÃO}

Desde a época mais distante, a negociação existe em nossas vidas. Quer percebamos ou não, estamos sempre gastando energia e recursos para negociar o que queremos,

RC: 84723

Disponível em: https://www.nucleodoconhecimento.com.br/administracao/processosoperacionais 
mas algumas pessoas não conseguem negociar formalmente quando chegam à mesa de negociações. Um simples fato pode perder uma boa oportunidade porque não percebemos que algumas situações precisam ser resolvidas amigavelmente.

Para Carvalhal (2015, p. 231) o processo de negociação é a forma básica de obter o que deseja dos outros. O autor disse ainda que se trata de uma troca de mão dupla, cujo objetivo é chegar a um acordo quando as duas partes têm interesses comuns e outros opostos.

$\mathrm{Na}$ opinião de Stoeckicht $(2015$, p. 150) a flexibilidade é crucial no processo de negociação, pois visões rígidas podem levar ao fracasso. Outro ponto muito importante na negociação é a honestidade, pois comportamentos desonestos podem ter consequências indesejáveis no futuro, prejudicando uma ou duas partes.

Em suma, a negociação refere-se ao processo de busca de ideias, objetivos ou benefícios que visam ao melhor resultado possível, de modo que as partes envolvidas percebam que ouviram suas opiniões e têm a oportunidade de apresentar todos os seus argumentos ao concluir a negociação, e produto final é maior que a soma das contribuições individuais.

\subsection{ERP}

A tecnologia vem evoluindo de forma bastante expressiva, mesmo com a oscilação da economia, a elevada oferta de crédito e desenvolvimento de novos mercados aumentam significativamente a competitividade das empresas. E para continuarem crescendo, as organizações precisam contar com gerenciamento correto de seus recursos, dados e processos. Um dos métodos mais utilizados para isso é a adoção de soluções de ERP (Enterprise Resource Planning).

$\mathrm{Na}$ visão de Nazaré et al. (2018) o ERP são sistemas interligados, que utilizam um mesmo banco de dados simplificando o fluxo de dados entre todas as áreas de uma

RC: 84723

Disponível em: https://www.nucleodoconhecimento.com.br/administracao/processosoperacionais 
empresa. Integrando as informações e técnicas de diversos setores, permitindo a automação e armazenamento de todas as informações da organização.

Do ponto de vista de Oliveira et al. (2016) o sistema ERP é a integração vista como a ligação conjunta de dados e transação de processos de setores distintos da organização, presente entre funções ou entidades operacionais da empresa.

Os benefícios dos sistemas ERP são: integração de funções e dados, interação com os fornecedores e clientes por meio de ferramentas como CRM (customer Relationship Management), aumento de vendas e diminuição de custos, melhores qualidades de serviços têm levado empresas adotarem sistemas como este.

\subsection{INDICADORES}

O processo de administração de qualquer empresa se estrutura nas fases de planejamento estratégico, planejamento operacional, execução e controle. Para essa fase de controle tem por objetivo assegurar, por meio da correção de "rumos", que os resultados planejados sejam efetivamente realizados, apoiando-se na avaliação de resultados e desempenho.

Para Almeida e Callado (2017, p. 224) atualmente, o levantamento é feito a partir de um levantamento envolvendo muitas variáveis, que requerem grande atenção dos gestores, como indicadores: satisfação do cliente, qualidade do produto, market share, fidelização do cliente, fidelização do cliente, inovação, estratégia de competências.

Santos e Dos Santos (2018, p. 119) os indicadores de desempenho são ferramentas relacionadas ao monitoramento e auxílio ao desenvolvimento de qualquer empresa. O indicador monitora o andamento da vida da organização e mostra se a estratégia é eficaz ou se o currículo e o plano precisam ser alterados.

Esses indicadores são dados concretos, mas se as informações fornecidas aos dados não forem verificadas de acordo com a situação real da empresa, podem estar

RC: 84723

Disponível em: https://www.nucleodoconhecimento.com.br/administracao/processosoperacionais 
errados. São o resultado de dois ou mais fatores que nos mostram como a empresa atua.

\section{MATERIAIS E MÉTODOS}

A metodologia do trabalho envolve um plano detalhado de tudo o que será feito na pesquisa. Portanto, a metodologia demonstra exatamente como sua pesquisa foi conduzida para que os resultados da pesquisa possam ser reproduzidos com fidelidade (KOCHE, 2016, p. 89).

\subsection{PROCEDIMENTOS METODOLÓGICOS}

O presente projeto foi realizado por meio de coleta e manejo de informações dentro da empresa Fênix Import - Assistência Técnica, tendo como finalidade a melhoraria os resultados operacionais através da otimização dos processos de gestão de compras.

\subsubsection{QUANTO À NATUREZA}

O presente trabalho é de natureza básica e pesquisa com objetivo de melhorar as teorias científicas para otimizar a previsão ou compreensão de fenômenos naturais. Sendo assim refere-se a pesquisas destinadas a aumentar nossa base de conhecimento científico (ESTRELA, 2018, p. 132).

\subsubsection{QUANTOS AOS FINS}

Quanto aos fins este trabalho é uma pesquisa descritiva, para que os fatos do mundo físico possam ser estudados, analisados, registrados e explicados sem a interferência dos pesquisadores. Exemplos de pesquisa descritiva são pesquisas de mercado e de opinião (KOCHE, 2016, p. 78). 


\subsubsection{QUANTO AOS MEIOS}

Para a realização deste trabalho, foi elaborado um estudo de caso no qual as possíveis soluções que a pesquisa desenvolveu podem ser visualizadas com mais detalhes para que o problema problemático seja identificado.

Esta pesquisa inclui um projeto que aborda métodos de pesquisa exploratória, em que atividades são realizadas para coletar dados e se esforçar para obter informações de pesquisa consistentes (GIL, 2017, p. 97).

Este trabalho foi realizado por meio de pesquisas bibliográficas e de publicações já existentes. A pesquisa bibliográfica é uma modalidade de pesquisa desenvolvida a partir de documentos de domínio científico tais como livros, periódicos, enciclopédias, ensaios críticos, dicionários e artigos científicos, tese e dissertações (ZANELLA, 2013, p. 76).

\subsection{CARACTERÍSTICAS DA EMPRESA}

FÊNIX IMPORT - ASSISTÊNCIA TÉCNICA, com CNJP: 35.561.413/0001-20, e de Inscrição Estadual: 1380137107-5. Localizada na Endereço: Av. Eduardo Ribeiro, № 457 - Centro, Manaus - AM, 69010-000. Atualmente o contato principal da empresa é Adriana Silva Defente, com E-mail: adriana.defente@gmail.com e Telefone: (92) 99228-1557. Fundada no ano de 2008 na Rua Marcílio Dias, Centro Histórico de Manaus. Pelos sócios Paulo Prossi (pai) e Thiago Prossi (filho).

Que iniciaram suas atividades com vendas de pequenos produtos eletrônicos, acessórios e celulares analógicos inicialmente para vendedores ambulantes, em seguida para pequenos camelos e posteriormente para pequenos comerciantes tanto da Capital, quanto do interior. Conseguindo com a vendas dessas mercadorias os recursos que financiariam as viagens e compras posteriores até adquirir o volume expressivo que justificaria as futuras aquisições via transportadora.

RC: 84723

Disponível em: https://www.nucleodoconhecimento.com.br/administracao/processosoperacionais 
Em 2018 nasceu a Fênix Assistência Técnica, a ideia ocorreu após um convite do Thiago a sua esposa Adriana Defente (que embora formada em administração e com bastante experiência com vendas e gestão de pessoas, nunca havia tido uma experiência pessoal com empreendedorismo) para montar uma filial com a venda do mesmo portfólio de produtos para o varejo e agregando a prestação de serviços expressos de consertos de celulares, tablets e notebooks.

É um bairro marcado pela diversidade de empresas comerciais e de serviços diversos. Seu quadro funcional está formado por 5 colaboradores subdivididos em suas áreas conforme suas respectivas funções. Alguns dos serviços oferecidos são: Celulares, Tabletes, Games, Notebooks Softwares.

Os principais clientes são: o público em geral é constituído por faixa etárias que vão de 18 anos até 60 anos. Os principais concorrentes são: Paulinho Cell, FG Cell, Manauara, Inforcell, Acesso Celulares. E os principais fornecedores são: empresas das chinesas de componentes.

\section{RESULTADOS E DISCUSSÕES}

De acordo com análise sobre o desempenho da empresa Fênix Import - Assistência Técnica é fruto de levantamento de dados referentes aos procedimentos da organização. Foi analisado através das entrevistas aplicadas com os administradores da empresa juntamente com os colaboradores da organização, que a empresa utiliza métodos de gestão de compras ineficaz, não obtendo resultados seguros a administração da empresa.

Abaixo veremos o gráfico de desempenho das áreas funcionais.

RC: 84723

Disponível em: https://www.nucleodoconhecimento.com.br/administracao/processosoperacionais 
Gráfico 1: Desempenho por área funcional.

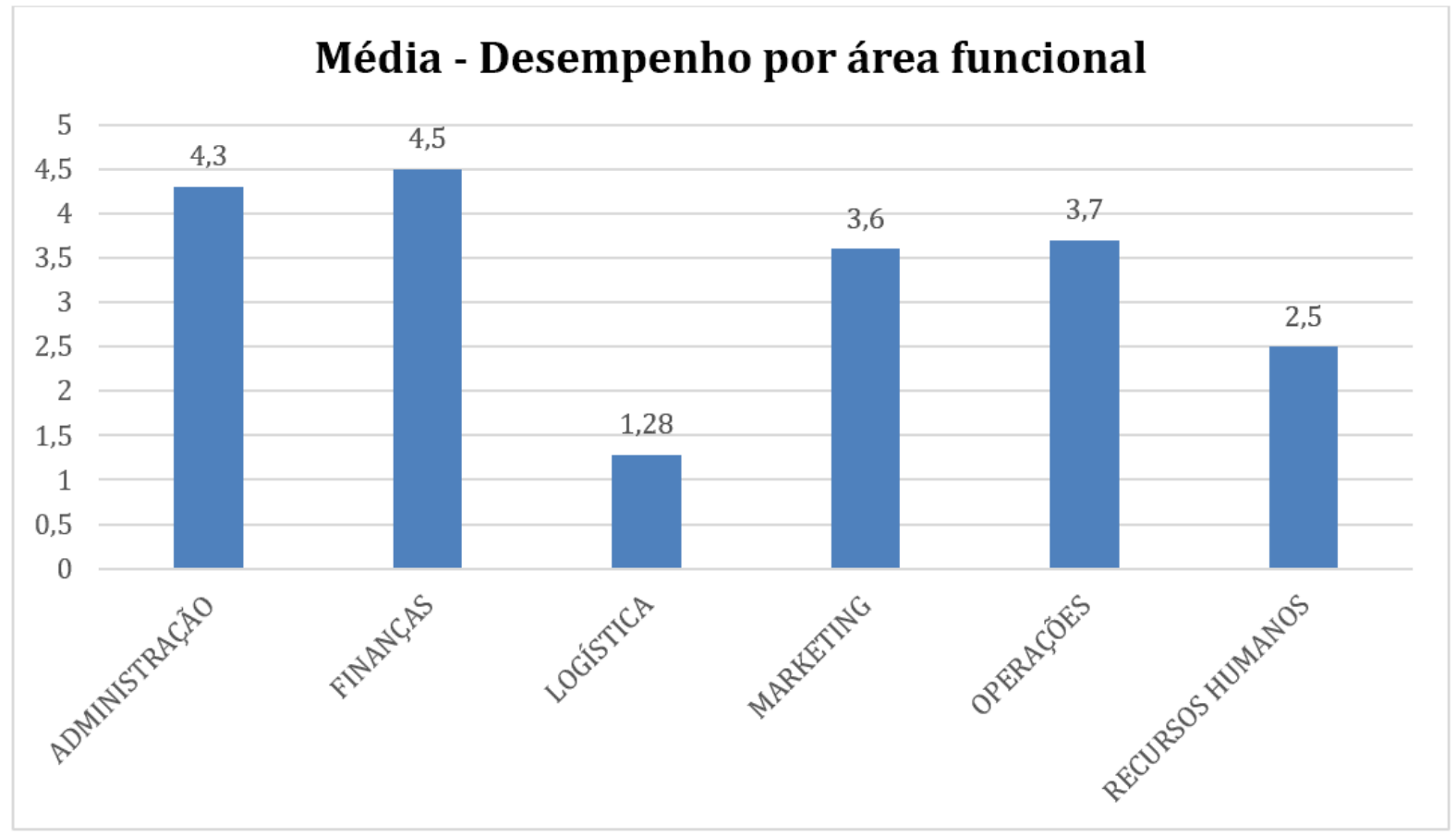

Fonte: Desenvolvido pelos autores, 2021.

O gráfico 01, apresenta que área com o pior desempenho funcional é de logística, sendo necessário uma intervenção para melhorar sua performance organizacional. Com base nos dados foi feita a elaboração da solução para que esse problema fosse solucionado de forma adequada e satisfatória para a empresa, colaboradores e clientes.

Assim, a tabela 01 apresenta uma descrição detalhada da performance da área de logística.

Quadro 1: Logística.

ÁREA FUNCIONAL

NIVEL OU GRAU DE
AVALIAÇÃO

RC: 84723

Disponível em: https://www.nucleodoconhecimento.com.br/administracao/processosoperacionais 


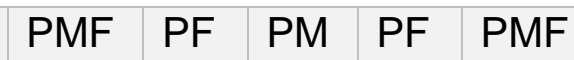

\begin{tabular}{ll|l|l|l}
5 & 4 & 3 & 2 & 1
\end{tabular}

1 A empresa possui tecnologia para estoque

2 A empresa realiza previsões e programações para manter seus estoques atualizados.

3 A empresa possui tecnologia com capacidade de integrar informações para avaliar o desempenho da cadeia de suprimentos.

4 A empresa utiliza Modais de Transporte com rotas flexíveis e viabilidade para diversos tipos de cargas.

5 Acuracidade no inventário Índice de atendimento do pedido

6 A empresa utiliza as tecnologias da informação e automação para minimizar as dificuldades nos processos operacionais

7 A empresa apresenta velocidade na entrega do serviço em tempo hábito.

8 Reposição de materiais

9 Negociação de fornecedores

10 Demora na resposta de cotações com fornecedor

TOTAL $(\Sigma)$

MÉDIA POR GRAU (POR COLUNA)

DESEMPENHO DA ÁREA

\begin{tabular}{|l|l|l|l|l|}
\hline 0 & 0,8 & 0,6 & 6 & 3 \\
\hline 0 & 0,1 & 0,3 & 0,6 & 0,3 \\
\hline 1,28 & & & &
\end{tabular}

Fonte: Desenvolvido pelos autores, 2021.

De acordo com 1, empresa apresenta uma dificuldade sobre a reposição de material, a gestão de compras não está garantindo que todos os suprimentos necessários para

RC: 84723

Disponível em: https://www.nucleodoconhecimento.com.br/administracao/processosoperacionais 
realizar as atividades da empresa sejam fornecidos em tempo suficiente para reposição. Na organização é notório que essa atividade não seja realizada de forma eficaz, as consequências podem ser a suspensão do produto e a perda de vendas, causando prejuízos ao negócio.

Percebe-se também que a empresa tem demonstrado uma fragilidade, ou seja, a maioria dos fornecedores são chineses, seja por falta de tempo ou por considerarem a importância de estreitar relacionamentos, a empresa só entra em contato com fornecedores quando absolutamente necessário. No entanto, uma comunicação regular e relações amigáveis com eles devem ser mantidas. Isso porque quanto mais você negocia e quanto mais próximo está do fornecedor, maior a chance de estabelecer uma relação comercial mais flexível.

A demora na cotação dos fornecedores, é compreendido que no mundo dos negócios não é só vendas, mas também compras pois o tempo gasto com a resposta de fornecedor é insuficiente para atendimento da empresa, visto que, os produtos em sua maioria são importados, a dependência de um estreitamento dessa relação é fundamental, para não ficar sem peças para venda.

A formulação da proposta de solução propõe uma melhoria na relação entre a empresa e o cliente, a partir das pesquisas realizadas. Por isso, busca uma ferramenta da qualidade que tenha como objetivo recomendar programas de desenvolvimento de processos internos para atrair mais clientes. Para tanto, foi elaborado um plano com base na ferramenta $5 \mathrm{~W} 2 \mathrm{H}$, e a análise do plano foi elaborada para auxiliar na elaboração de um plano de ação, melhorando a clareza da equipe sobre as atividades a serem realizadas.

RC: 84723

Disponível em: https://www.nucleodoconhecimento.com.br/administracao/processosoperacionais 


\subsection{PLANEJAMENTO DE AÇÕES}

No que corresponde ao quadro 2, refere-se ao planejamento de ação que inclui o delineamento de várias etapas que detalham as operações que serão realizadas de acordo com a estratégia adotada para atingir os objetivos da empresa.

Quadro 2: Ações interventivas

\begin{tabular}{|l|l|l|l|l|l|}
\hline Item & $\begin{array}{l}\text { Ações Interventivas } \\
11\end{array}$ & $\begin{array}{l}\text { Elaborar um mapeamento da } \\
\text { empresa e estruturação de } \\
\text { processos }\end{array}$ & cronologia & cronologia & Custo \\
\hline 22 & $\begin{array}{l}\text { Estruturar um plano de treinamento } \\
\text { voltado a gestão de fornecedores }\end{array}$ & abr/21 & 15 dias & $\mathrm{R} \$ 1.000,00$ \\
\hline 33 & $\begin{array}{l}\text { Categorizar os fornecedores no } \\
\text { cenário nacional e internacional. }\end{array}$ & mai/21 & 7 dias & $\mathrm{R} \$ 1.000,00$ \\
\hline 44 & $\begin{array}{l}\text { Construir uma relação com } \\
\text { fornecedores para manutenção de } \\
\text { "Follow up" com as compras. }\end{array}$ & mai/21 & 8 dias & $\mathrm{R} \$ 1.200,00$ \\
\hline 55 & $\begin{array}{l}\text { Selecionar a inserção do } \\
\text { Planejamento de Recursos de }\end{array}$ & mai/21 & 5 dias & $\mathrm{R} \$ 2.500,00$ \\
\hline 66 & $\begin{array}{l}\text { Produção (MRP 1). } \\
\text { Implementação sistema de ERP de } \\
\text { gestão de compras }\end{array}$ & mai/21 & 10 dias & $\mathrm{R} \$ 1.000,00$ \\
\hline 77 & $\begin{array}{l}\text { Realizar análise sobre os KPl"s } \\
\text { TOTAL jun/21 }\end{array}$ & 1 dia & $\mathrm{R} \$ 500,00$ \\
\hline
\end{tabular}

Fonte: Desenvolvido pelos autores, 2021. 


\subsubsection{MAPEAMENTO DA EMPRESA E SUA ESTRUTURAÇÃO}

De acordo com o quadro 3, a primeira etapa consiste em mapear os processos da organização que possibilitarão uma melhor estruturação da empresa, a partir da identificação dos problemas e gargalos atuais, será definida uma nova forma de desenvolvimento das tarefas, para um melhor controle organizacional.

Quadro 3: 5W2H - Mapeamento da empresa e estruturação de processos.

\begin{tabular}{|l|l|}
\hline $\begin{array}{l}\text { Mapeamento do negócio para fidelização do cliente e configuração dos } \\
\text { processos }\end{array}$ & \\
\hline O que? & Mapeamento da empresa e estruturação de processos \\
\hline Por quê? & Obtenção de maiores informações sobre a empresa \\
\hline Onde? & Fênix Import - Assistência Técnica \\
\hline Quando? & primeira quinzena de abril/2021 \\
\hline Quem? & Setor de Compras \\
\hline Como? & Mediante ao diagnóstico da empresa \\
\hline Quanto? & $\mathrm{R} \$ 1000,00$ \\
\hline
\end{tabular}

Fonte: Desenvolvido pelos autores, 2021.

\subsubsection{ESTRUTURAÇÃO DE UM PLANEJAMENTO DE TREINAMENTO PARA GESTÃO DE FORNECEDORES}

De acordo com o quadro 4, a segunda etapa consiste em estruturar a gestão de fornecedores assim capacitando o setor da empresa para um patamar estratégico, essencialmente no que diz a respeito à busca da excelência da gestão de cadeia de suprimentos, pois é compreendido como este é um insumo de suma relevância para o sucesso do negócio. 
Quadro 4: 5W2H - Estruturação de um planejamento de treinamento para gestão de fornecedores.

Estruturação de um planejamento de treinamento para gestão de fornecedores

O que? Capacitação e treinamento de fornecedores

Por quê? Para atualização e domínio sobre as ferramentas dos fornecedores

Onde? Fênix Import - Assistência Técnica

Quando? Segunda quinzena de abril/2021

Quem? Setor de Compras

Como? Por meio de cursos e parceria com os fornecedores

Quanto? $\mathrm{R} \$ 2.000,00$

Fonte: Desenvolvido pelos autores, 2021.

\subsubsection{IMPLEMENTAÇÃO E CATEGORIZAÇÃO DOS FORNECEDORES NO CENÁRIO NACIONAL E INTERNACIONAL}

De acordo com o quadro 5, a terceira etapa consiste em implementar um melhor processo de seleção de fornecedores. Visto que, conforme a demanda aumenta ou diminui, a complexidade aumentará de acordo com as características dos bens ou serviços a serem adquiridos.

Neste caso, os critérios de avaliação e seleção de fornecedores podem ser usados no contexto da gestão da cadeia de abastecimento. Parte da estratégia de compra é definir com quantos e quais fornecedores a empresa trabalhará e quais as suas localidades. 
Quadro 5: 5W2H - Implementação e categorização dos fornecedores no cenário nacional e internacional.

\section{Implementação e categorização dos fornecedores no cenário nacional e internacional}

O que? Capacitação e treinamento de fornecedores

Por quê? Para melhor escolha de fornecedores e suas características

Onde? Fênix Import - Assistência Técnica

Quando? Primeira semana de maio/2021

Quem? Setor de Compras

Como? Análise de fornecedores

Quanto? R\$1.000,00

Fonte: Desenvolvido pelos autores, 2021.

\subsubsection{CONSTRUÇÃO DE UMA MELHOR RELAÇÃO COM FORNECEDORES}

De acordo com o quadro 6, a quarta etapa consiste em uma construção de uma melhor e próxima relação com os fornecedores. Pois, a gestão das relações com fornecedores contém uma das mudanças mais significativas, como a empresa atua em seu ambiente de negócios. Ao avaliar custos, confiabilidade na entrega e qualidade do produto, os gerentes buscam gerenciar melhor os recursos alocados às empresas fornecedoras e avaliar oportunidades para garantir a relação custobenefício.

Quadro 6: 5W2H - Construção de uma melhor relação com fornecedores.

\section{Implementação de uma melhor relação com fornecedores}

\begin{tabular}{|l|l|}
\hline O que? & Alinhamento de processos e negócios \\
\hline Por quê? & Para melhora da relação com fornecedores
\end{tabular}

RC: 84723

Disponível em: https://www.nucleodoconhecimento.com.br/administracao/processosoperacionais 


\begin{tabular}{|l|l|}
\hline Onde? & Fênix Import - Assistência Técnica \\
\hline Quando? & Segunda semana de maio/2021 \\
\hline Quem? & Setor de Compras \\
\hline Como? & Criação de uma forte parceria \\
\hline Quanto? & $\mathrm{R} \$ 1.200,00$ \\
\hline
\end{tabular}

Fonte: Desenvolvido pelos autores, 2021.

\subsubsection{IMPLEMENTAÇÃO DO PLANEJAMENTO DE RECURSOS DE PRODUÇÃO (MRP 1)}

De acordo com o quadro 7, a quinta etapa consiste em à implementação do MRP 1, no qual a análise será desenvolvida por um sistema projetado para planejar a quantidade de materiais necessários para a aquisição para atender aos requisitos específicos de vendas de produtos.

Quadro 7: 5W2H - Implementação do Planejamento de Recursos de Produção (MRP 1).

\begin{tabular}{|l|l|}
\hline Implementação do Planejamento de Recursos de Produção (MRP 1) \\
\hline O que? & Alinhamento de processos e negócios \\
\hline Por quê? & Otimização de cálculo de necessidade de materiais \\
\hline Onde? & Fênix Import - Assistência Técnica \\
\hline Quando? & Terceira semana de maio/2021 \\
\hline Quem? & Setor de Compras \\
\hline Como? & Por meio de imputação de dados \\
\hline Quanto? & $\mathrm{R} \$ 2.500,00$ \\
\hline
\end{tabular}

Fonte: Desenvolvido pelos autores, 2021. 


\subsubsection{IMPLEMENTAÇÃO DE UM SISTEMA DE GESTÃO DE COMPRAS}

De acordo com o quadro 8, a sexta etapa do processo de implementar um ERP de compras, gerenciar as informações e o controle de dados que cada produto da empresa e pode acessar. Sem falar em melhorar o controle de estoque, padronizar processos, reduzir riscos, melhorar a gestão de recursos.

Quadro 8: 5W2H - Implementação de um Sistema de gestão de compras.

\begin{tabular}{|l|l|}
\hline Implementação de um Sistema de gestão de compras \\
\hline O que? & Alinhamento de processos e negócios \\
\hline Por quê? & Para otimização dos dados da empresa de compras \\
\hline Onde? & Fênix Import - Assistência Técnica \\
\hline Quando? & Quarta semana de maio/2021 \\
\hline Quem? & Setor de Compras \\
\hline Como? & Inserção do software de compras na empresa \\
\hline Quanto? & $\mathrm{R} \$ 1.000,00$ \\
\hline
\end{tabular}

Fonte: Desenvolvido pelos autores, 2021.

\subsubsection{REALIZAR REUNIÃO DE KPI'S}

Segundo o quadro 9, a última etapa é realizar reunião mensal onde será incluído todas as informações geradas pelo sistema de compilação, que é um indicador de desempenho que fornece as medidas necessárias para que a organização alcance seus objetivos.

Quadro 9: 5W2H - Realizar reunião de KPI's.

\section{Realizar análise de métrica.}

O que? Realizar análise sobre dados da empresa mensalmente 


\begin{tabular}{|l|l|}
\hline Por quê? & Para analisar a viabilidade do processo \\
\hline Onde? & Fênix Import - Assistência Técnica \\
\hline Quando? & Primeira semana de junho/2021 \\
\hline Quem? & Setor de Marketing. \\
\hline Como? & Análise por meio de KPl's. \\
\hline Quanto? & $\mathrm{R} \$ 500,00$ \\
\hline
\end{tabular}

Fonte: Desenvolvido pelos autores, 2021.

\subsubsection{FLUXOGRAMA DA PROPOSTA DE SOLUÇÃO}

De acordo com a figura 1, foi elaborado um fluxograma com a sugestão melhorar os resultados operacionais através da otimização dos processos de gestão de compras, com o intuito de promover maior conhecimento para os mesmos sobres, como gerir da melhor a gestão de compras da empresa.

A técnica de mapeamento escolhida para o estudo de caso é um fluxograma, pois entre outras técnicas, é a técnica que melhor se adapta à situação real da empresa e fornece as informações necessárias para o tipo de trabalho executado (ou seja, pedido). Tarefas, decisões e espera para parar.

O processo de mapeamento requer observação e descrição de como você trabalha. Quanto mais realistas e precisas forem essas medidas, melhor será a análise da situação atual e mais bem-sucedida será a melhoria. 
Figura 1: Fluxograma da proposta

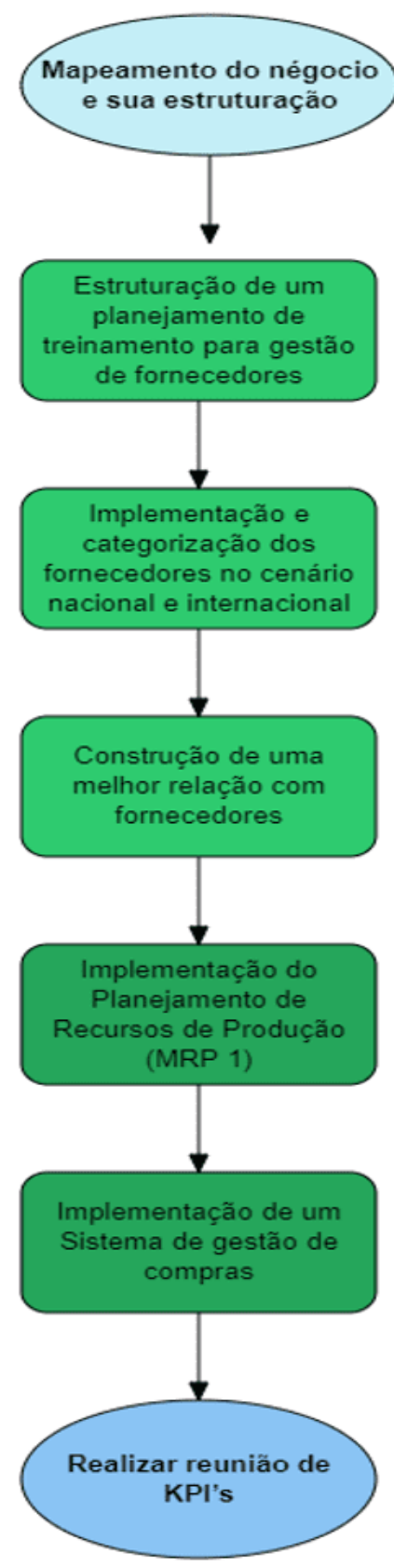

Fonte: Elaborado pelo acadêmico.

RC: 84723

Disponível em: https://www.nucleodoconhecimento.com.br/administracao/processosoperacionais 


\section{CONSIDERAÇÕES FINAIS}

Diante dos fatos apresentados no diagnóstico organizacional, identificou à problemática do estudo de caso na empresa Fênix Import - Assistência Técnica, sendo no setor de logística que demonstrou as incidências e inconformidades, por meio da coleta de dados. O gráfico de avaliação de áreas mais críticas apontou que a empresa apresenta os problemas a serem melhorados, tais como nos processos operacionais de gestão de compras.

Foram identificados e apresentados os aspectos e características que guiam o agir da empresa, natureza do negócio, missão, visão, valores e princípios. O objetivo desta pesquisa foi melhorar os resultados operacionais através da otimização dos processos de gestão de compras. Os aspectos operacionais são pontuados para entender o que precisa ser modificado ou não. Também foi realizado um estudo bibliográfico para investigar e diagnosticar os elementos utilizados para implementar ferramentas de gestão que possam melhorar o desempenho da Fênix Import- Assistência Técnica.

No estudo de caso, foram realizadas análises internas e externas para chegar aos resultados sugeridos no projeto. A aplicação do método seguiu o padrão de entrevistas com gestores, funcionários e clientes, que expressaram a falta de uma forma de divulgar o projeto para atrair mais clientes.

Portanto, a fim de buscar estratégias e soluções viáveis com base nas necessidades atuais da organização e realidade logística, recomenda-se a utilização da ferramenta 5W2H como método de melhoria contínua para implementar um plano de ação para o problema alcançar a solução.

Contudo, o objetivo do nosso trabalho foi alcançado com êxito através de análises das pesquisas realizadas, foi desenvolvido um projeto para melhorar os resultados operacionais através da otimização dos processos de gestão de compras. Resumindo, é recomendável que as organizações mantenham seus processos inalterados para

RC: 84723

Disponível em: https://www.nucleodoconhecimento.com.br/administracao/processosoperacionais 
manter relacionamentos de longo prazo com seus provedores de serviços, partes interessadas e consumidores.

\section{REFERÊNCIAS}

ALMEIDA, Karla Katiuscia Nóbrega; CALLADO, Aldo Leonardo Cunha. Indicadores de desempenho ambiental e social de empresas do setor de energia elétrica brasileiro: uma análise realizada a partir da ótica da Teoria Institucional. Revista de Gestão, Finanças e Contabilidade, v. 7, n. 1, p. 222-239, 2017.

CARVALHAL, Eugenio. Negociação e administração de conflitos. Editora FGV, 2015.

COTI-ZELATI, Paolo Edoardo; MOORI, Roberto Giro. O papel da colaboração no desempenho da gestão da cadeia de suprimentos: um estudo sobre o café orgânico. Organizações Rurais \& Agroindustriais, v. 17, n. 2, p. 195-208, 2015.

ESTRELA, Carlos. Metodologia científica: ciência, ensino, pesquisa. Artes Médicas, 2018.

GIL, Antônio Carlos. Como Elaborar Projetos De Pesquisa. 6.ed. São Paulo: Atlas, 2017.

GOMES, Carlos Francisco Simões; RIBEIRO, Priscilla Cristina Cabral. Gestão da cadeia de suprimentos integrada à tecnologia da informação. ed. Senac Rio, 2020.

GOMES, Leonardo de Carvalho; NETO, Francisco José. Métodos colaborativos na gestão de cadeias de suprimentos: desafios de implementação. Revista de administração de empresas, v. 55, n. 5, p. 563-577, 2015. 
GOMES, Renato Pereira; MILAN, Willyan Wilson. Gestão de estoque pelo método do estoque máximo-mínimo em uma empresa de médio porte do ramo de revenda de combustível em Carneirinho-MG. Revista Eletrônica Organizações e Sociedade, v. 6, n. 5, p. 19-36, 2017.

KÖCHE, José Carlos. Fundamentos de metodologia científica. ed. Vozes, 2016.

MAGALHÃES, Eduardo. Gestão da cadeia de suprimentos. Ed. FGV, 2015.

MEDEIROS, Rubens Martendal; PEREIRA, Jaiane Aparecida. Gestão Estratégica Da Produção E Operações: um estudo sobre a fabricação de concreto usinado. Encontro Internacional de Gestão, Desenvolvimento e Inovação (EIGEDIN), v. 2, n. 1, 2018.

MONTE, Antonio Mendes Pinheiro Clelio Feres. Técnicas de compras. ed. FGV, 2015.

NAZARÉ, Tiago Bittencourt et al. Implementação de conceitos de ERP como apoio na gestão da produção de uma tornearia de pequeno porte. Revista Mythos, v. 10, n. 2, p. 119-128, 2018.

OLIVEIRA, Sirlei Aparecida et al. Utilização de soluções ERP em Micro e Pequenas Empresas. Cadernos UniFOA, v. 11, n. 30, p. 83-92, 2016.

PAOLESCHI, Bruno. Almoxarifado e Gestão de Estoques-Do recebimento, guarda e expedição à distribuição do estoque. Saraiva Educação SA, 2018.

PAOLESCHI, Bruno. Estoques e armazenagem. Saraiva Educação SA, 2018.

PEREIRA, Cynara F. et al. Estudo de caso: aplicação da ferramenta mrp em uma microempresa de confeitaria. In: Simpósio de Engenharia de Produção. 2016. 
SANTOS, Bruno Teixeira; LUBIANA, Cleidice. O uso da curva ABC para a tomada de decisão na composição de estoque. Inter-American Journal of Development and Research, v. 1, n. 1, p. 62-78, 2017.

SANTOS, Pedro Vieira Souza; DOS SANTOS, Lucas Di Paula Gama. Gestão de indicadores: um estudo de caso no setor de serviços. Brazilian Journal of Production Engineering-BJPE, p. 115-133, 2018.

SOUSA, Adail José et al. Controladoria na Gestão de Compras como Estratégia na Busca da Eficiência e Otimização do Resultado Econômico. Management Control Review, v. 1, n. 1, p. 43-58, 2016.

STOECKICHT, Ingrid Paola. Negociação internacional. Editora FGV, 2015.

ZANELLA, Liane Carly Hermes. Metodologia De Pesquisa. 2. ed. Reimp. Florianópolis: Departamento De Ciências Da Administração/Ufsc, 2013.134.

Enviado: Março, 2021.

Aprovado: Maio, 2021. 